\title{
Socioeconomic Roots of Academic Faculty
}

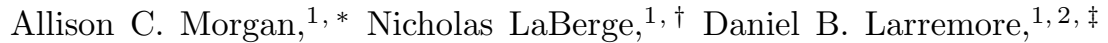 \\ Mirta Galesic, ${ }^{3,3}$ Jennie E. Brand,, 4 , and Aaron Clauset ${ }^{1,2,3, * *}$ \\ ${ }^{1}$ Department of Computer Science, University of Colorado, Boulder, CO, USA \\ ${ }^{2}$ BioFrontiers Institute, University of Colorado, Boulder, CO, USA \\ ${ }^{3}$ Santa Fe Institute, Santa Fe, NM, USA \\ ${ }^{4}$ University of California, Los Angeles, CA, USA
}

\begin{abstract}
Despite the special role of tenure-track faculty in society, training future researchers, and producing scholarship that drives scientific and technological innovation, the sociodemographic characteristics of the professoriate have never been representative of the general population. Here we systematically investigate the indicators of faculty childhood socioeconomic status and consider how they may limits efforts to diversify the professoriate. Combining national-level data on education, income, and university rankings with a 2017-2020 survey of 7,204 U.S.-based tenure track faculty across eight disciplines in STEM, social science, and the humanities, we show that faculty are up to 25 times more likely to have a parent with a $\mathrm{PhD}$. Moreover, this rate nearly doubles at prestigious universities and is stable across the past 50 years. Our results suggest that the professoriate is, and has remained, accessible disproportionately to the socioeconomically privileged, which is likely to deeply shape their scholarship and their reproduction.
\end{abstract}

\section{INTRODUCTION}

Professors play a unique role in the knowledge economy: they both train the next generation of thinkers and generate new scholarship, which informs national policy and advances scientific discoveries. But the professoriate has never represented the sociodemographic characteristics of the population it serves. While the diversity of the educational pipeline has been extensively studied in terms of race and ethnicity [1-3], and the links between parental income and occupational status, and their children's educational attainment are well documented [47, there exist comparatively few systematic studies on the socioeconomic roots of professors or how their socioeconomic origins interact with institutional prestige. Analyses of the socioeconomic backgrounds of faculty will both improve our understanding of the social reproduction of the highest levels of academic attainment and scientific influence, and shed new light on how representational diversity influences which and what kind of discoveries are made.

From early childhood through advanced degree attainment, family socioeconomic origins shape educational outcomes [8. Parental socioeconomic status (SES) impacts children's educational attainment in numerous ways. Higher SES parents, who tend to be collegeeducated and occupy high status occupations, cultivate advantaged cultural and social capital for their children [9. High SES parents also engage in "concerted cultivation," whereby parents prioritize organized activ-

\footnotetext{
* allison.morgan@colorado.edu

† nicholas.laberge@colorado.edu

$\ddagger$ daniel.larremore@colorado.edu

$\S$ galesic@santafe.edu

ศ brand@soc.ucla.edu

** aaron.ciauset@coiorado.edu
}

ities that facilitate educational success [10, and spend an increasingly large amount of time on developmental activities that advantage their children's attainment 7 . Families with high SES parents also have more information about schooling and resourceful social networks than working-class families. Research also suggests that middle- and upper-class students request accommodations and attention in school that ultimately advantage them in their attainment [11. These networks function through power and privilege across racial, ethnic, and social class lines, forming unequal opportunities for academic success. SES and race also impact where families live and the schools that children attend. The dispositions and skills of high SES students are judged differently by teachers and other school personnel who favor the cultural capital of middle and upper-class youth [12. Ultimately, parents, teachers, and students behave in ways that reproduce class and racial inequality in academic achievement [9]. Schools in more and less advantaged neighborhoods differ markedly in resources available to students [13, 14]. These factors all contribute to the substantial effects of family SES on post-secondary schooling.

Research has shown notable socioeconomic differences in not only whether individuals attend and complete college, but also where they attend, with more advantaged students attending more selective institutions. Students completing degrees at highly selective institutions are more likely to come from the top $1 \%$ of the U.S. income distribution than from the bottom $50 \%$ [15. Students from more disadvantaged socioeconomic backgrounds who attend college, particularly those who attend selective colleges, also have different experiences on campus that are less conducive to academic success than their higher socioeconomic peers [16, 17.

Family SES also influences graduate school applications and admissions [18, as well as students' experiences once accepted [19, 20]. In fact, graduate and professional 
degrees are substantially more heritable that other levels of education. Individuals with parents who have a doctorate or professional degree are increasingly overrepresented among doctorate and professional degree holders [20]. Moreover, research on social mobility suggests that the association between parents' SES and their children's status is larger among post-graduate than bachelor's degree recipients $[19,20]$. Occupational closure plays an important role in the intergenerational transmission of status [21, and an association between children and their parents' occupations (sometimes called micro-class reproduction) has persisted for decades 22. Unequal social, cultural, and financial capital help reproduce microclass advantages across generations, and the professoriate may be an occupation with a high level of closure and reproduction.

The accumulation and consequences of these tendencies can be expected to limit the socioeconomic diversity of the professoriate. However, the extent and shape of this association, and its precise interactions with gender, race, ethnicity, academic discipline, and prestige are less well understood. Past work shows that faculty are increasingly representative of highly educated families [23], while professors from disadvantaged socioeconomic backgrounds report hyper-awareness of how those backgrounds impact their careers [24], which can make them feel like outsiders in academia 25. Socioeconomic status may also interact with academic job placement. Vague narrow definitions of merit or "fit" disadvantage the work of marginalized scholars, particularly racial minorities [26] or those from working class or poor backgrounds [27, due to differences in social and cultural capital between these applicants and faculty search committees [21. Structural factors that influence whether and where a person earns a faculty job, as well as difficulties once employed, will influence the composition of the professoriate.

Beyond composition alone, representational diversity is known to improve academic scholarship 28, and a lack of socioeconomic diversity is likely to deeply shape the type of scholarship that faculty produce and the scholars they train. Recent studies have begun quantifying how researcher identity affects research topic choices 29], as well as the evaluation of that work [30, 31]. However, it remains generally unclear what scholarship is missing as a result of limited representational diversity across the professoriate, in part because we lack a clear and quantitative view of current diversity and its roots.

Here, we develop such a view by investigating the indicators of childhood SES of U.S.-based tenure-track professors across eight disciplines spanning science, technology, engineering, and mathematics (STEM), the social sciences, and the humanities. Tenure-track faculty positions are less financially precarious than contingent positions, rendering the socioeconomic representation of the faculty who obtain these privileged positions notable for social reproduction. We consider how SES systematically shapes faculty placement within academia, how the role of SES varies across broad disciplines, and how parental advanced degrees influence the likelihood that their children become and remain as faculty. We conclude by suggesting how socioeconomic diversity and its historical trends may limit diversity in the professoriate.

\section{DATA \& METHODS}

To study the childhood SES of U.S. faculty we conducted a large representative survey of tenure-track faculty at PhD-granting departments in the United States from eight academic disciplines. Responses include information on the education levels of parents and the ZIP code where faculty grew up. This protocol was approved by the University of Colorado Boulder Institutional Review Board. All participants were included in drawings for a cash lotteries (SI A). We augment our survey data with national estimates of educational attainment, income, and rural or urban classification by ZIP code from the U.S. Census, National Science Foundation (NSF) Survey of Earned Doctorates (SED), Internal Review Service (IRS), U.S. News and World Report (USNWR), and the National Research Council (NRC), which allow us to contrast survey characteristics with patterns in the general U.S. population.

We conducted the online survey between Summer 2017 and Fall 2020 on a frame of 46,692 current tenure-track faculty across 1,360 PhD-granting departments in Computer Science, Business, History, Psychology, Physics \& Astronomy, Sociology, Anthropology, and Biology. Though contingent faculty represent an increasing proportion of the U.S. academic workforce, we surveyed tenure-track faculty because their unique stability in academia makes them more likely to contribute research and mentor scholars over the course of their careers. These eight academic disciplines were chosen for their diversity of scholarship and represent a broad sample of tenure-track faculty at research intensive institutions in the U.S. The sample frame was constructed from the online public directories of institutions, allowing us to explicitly compare respondents with the frame.

In total, 7,204 faculty provided information on a parent's level of highest education (15.4\% of survey frame) and 4,807 provided the U.S. ZIP code in which they grew up $(10.3 \%)$. Overall, our response rate resembles other online surveys with email invitations conducted in the context of academia 32, 33. While it is not possible to know whether faculty respondents differ in their childhood SES from those who did not respond, respondents were generally representative of their fields by institutional prestige and faculty rank. Additionally, women responded at slightly higher rates than expected in several disciplines (Table S1). This pattern may imply a slight upward bias in our analysis of parents' education: in our sample, women are somewhat more likely to come from highly educated families (one of their parents holds a PhD: $24.8 \%$ vs $20.8 \%$; $z=3.9, N=7,145, p<0.001)$, 
across all disciplines (Table S2 . Roughly a quarter of respondents provided a country outside of the U.S. where they grew up $(N=2,007 ; 25.1 \%)$, consistent with prior estimates of the proportion of international faculty at U.S. universities 34.

We asked faculty to reflect on their childhood and report their parents' highest levels of education during this period (SI A). We compare their responses to the adult educational attainment statistics in the U.S. population in the year the survey respondent was born [35, and to educational attainment of parents of U.S. doctoral recipients in the year they graduated from their doctoral program [36. These benchmarks respectively facilitate comparisons of faculty with the general public, and with academics at a career stage just prior to their current one. Comparing faculty to national estimates describe how privileged the upbringings of faculty were relative to the general public, and comparisons to doctoral recipients describes how the socioeconomic roots of faculty differ from the broader set of their doctoral peers.

Data on the educational attainment of adults are drawn from the American Community Survey of the U.S. Census, and information on family's educational attainment among PhD recipients is drawn from the NSF SED. While historical data on undergraduate and graduate achievement is available from the NSF [37, it does not report demographics as percentages of the adult population or describe any earlier education levels as we require. Prior to 1993, the Census recorded educational attainment as years of schooling, and completion (or not) of high school or bachelor's degree [38. More recent data recorded educational attainment as highest degree held among adults 25 years and older. In our study, we refer to both. Using the earlier census data, we compare parents' college completion among faculty to college completion rates in the adult U.S. population. When we require information on degree earned, we compare respondents to the census dataset closest to the year faculty were born that records this information.

Our estimates of U.S. adult PhD completion (from 1993 at the earliest) are likely higher than the true $\mathrm{PhD}$ completion rate in the year a respondent was born (which was 1967, on average), due to rising educational attainment in the U.S. Thus, our comparisons of faculty parents with the general public may in fact underestimate academia's overrepresentation of highly educated families. Data on the highest degree attained by parents of $\mathrm{PhD}$ recipients is available for select years from 1993 to 2018 from the NSF 36. Details on how many respondents matched with a given year of data are provided in $\mathrm{SIB}$.

Since childhood household income is also predictive of educational attainment, we construct proxy measures of childhood income levels and geographic diversity among current faculty. The ideal data set would be individuallevel household income and location during the childhoods of faculty. Because it is difficult for survey respondents' to estimate their parents' income retrospec- tively, we approximate these quantities using more easily recalled information. We link ZIP code responses to the closest publicly available IRS tax release (1998 to 2018) when faculty were children (adjusted to 2020 dollars). Proxying individual SES based on aggregate ZIP code level data is a widely-used approach [39, 40. However, the geographic proxy may suffer from some mismeasurement because ZIP codes often span heterogeneous populations 41. To measure whether faculty come from rural or urban areas, we use U.S. Census data from 1990 to 2010, linked to faculty responses by their year of birth [42, which records how many people live in urban or rural areas in a given ZIP code. We labeled ZIP codes as either rural or urban based on whether the majority of the population in that ZIP code lived in a rural or urban area. As with our measure of income, this approach may suffer from mismeasurement due to the underlying heterogeneity of a ZIP code. These measures of childhood household income and geographic diversity, when taken together with self-reported information on parental education, speak to how faculty socioeconomic status shapes academic careers.

Finally, to assess whether SES impacts job placement within academia, we compare the previously described measures with the institutional prestige of a respondent's current faculty appointment and $\mathrm{PhD}$ granting institution. For most of the disciplines considered here, we refer to 2017-2020 college rankings from USNWR, which is provided for most Carnegie-classified R1 and R2 doctoral universities. Because Anthropology departments are not ranked by USNWR, we use their R rank in the 2010 NRC Anthropology rankings. To account for differences in the number of departments across disciplines, we rescale each ranking to the unit interval. Where faculty were employed at institutions not ranked by USNWR or NRC (11.1\% of responses), we coded their ranking as missing and excluded them from our analysis of institutional prestige.

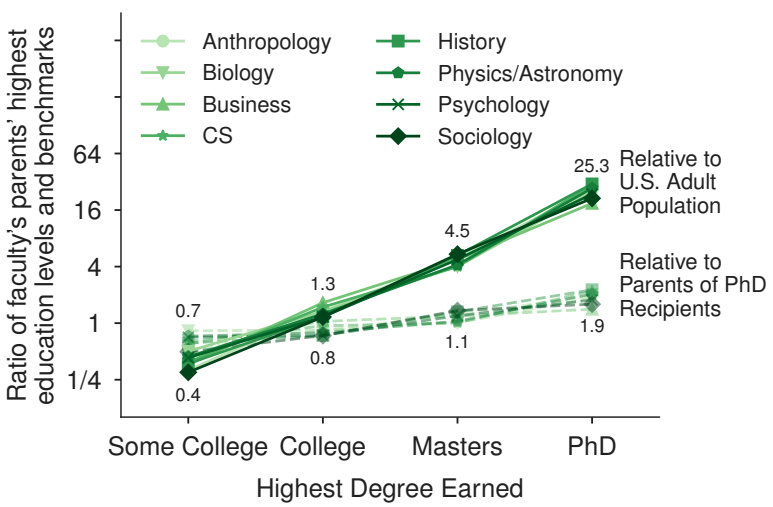

FIG. 1. Ratios of faculty parents' education to broader populations. Faculty members' parents' educational attainment levels divided by the educational attainment of the U.S. adult population (solid) and parents of $\mathrm{PhD}$ recipients (dashed) 35, 36. Disciplines denoted by symbols. 


\begin{tabular}{|c|c|c|c|c|c|c|}
\hline & Some HS or Less & HS & Some College & College & Masters & $\mathrm{PhD}$ \\
\hline All Professors & 5.5 & 13.7 & 9.5 & 19.5 & 29.6 & 22.2 \\
\hline Anthropology Professors & 3.1 & 14.9 & 7.3 & 19.4 & 32.1 & 23.1 \\
\hline Biology Professors & 6.5 & 14.3 & 11.6 & 19.5 & 26.2 & 21.9 \\
\hline Business Professors & 5.6 & 14.5 & 8.4 & 24.1 & 30.9 & 16.6 \\
\hline CS Professors & 6.6 & 10.8 & 8.9 & 21.6 & 26.1 & 26.0 \\
\hline History Professors & 2.9 & 10.5 & 8.6 & 17.0 & 34.3 & 26.7 \\
\hline Physics/Astronomy Professors & 8.2 & 12.1 & 10.2 & 18.3 & 27.3 & 24.1 \\
\hline Psychology Professors & 3.7 & 17.4 & 9.9 & 17.1 & 31.1 & 20.8 \\
\hline Sociology Professors & 4.5 & 17.4 & 6.9 & 17.0 & 35.3 & 18.8 \\
\hline Survey of Earned Doctorates (NSF) & \multicolumn{2}{|l|}{$\leftarrow 25.2 \rightarrow$} & 14.0 & 23.1 & 26.0 & 11.8 \\
\hline U.S. Population (Census) & 19.2 & 35.6 & 23.1 & 14.6 & 6.5 & 0.9 \\
\hline
\end{tabular}

TABLE I. Percentages of faculty by their parents' highest held degree, compared to the closest available data on educational attainment of the U.S. adult population when faculty were born and the education levels of the parents of doctoral recipients when faculty started their tenure-track job.

\section{RESULTS}

\section{Parents' Education}

Faculty tend to come from highly educated families. Nearly a quarter $(22.2 \%)$ report at least one of their parents holds a $\mathrm{PhD}$, and $3.7 \%$ of faculty report both parents hold PhDs. Across all eight disciplines, over half (51.8\%) of faculty have at least one parent with a masters degree or $\mathrm{PhD}$ (29.6\% and $22.2 \%$ respectively; Table I). In comparison, among adults in the U.S. aligned to when faculty were born, on average, less than $1 \%$ held a $\mathrm{PhD}$, and just $7.4 \%$ held a graduate degree of any kind.

We calculate the relative likelihood that a faculty has a parent with a $\mathrm{PhD}$, compared to either the U.S. adult population or to parents of $\mathrm{PhD}$ recipients, by estimating upper and lower bounds. These bounds correspond to differences in whether these data sets described individuals

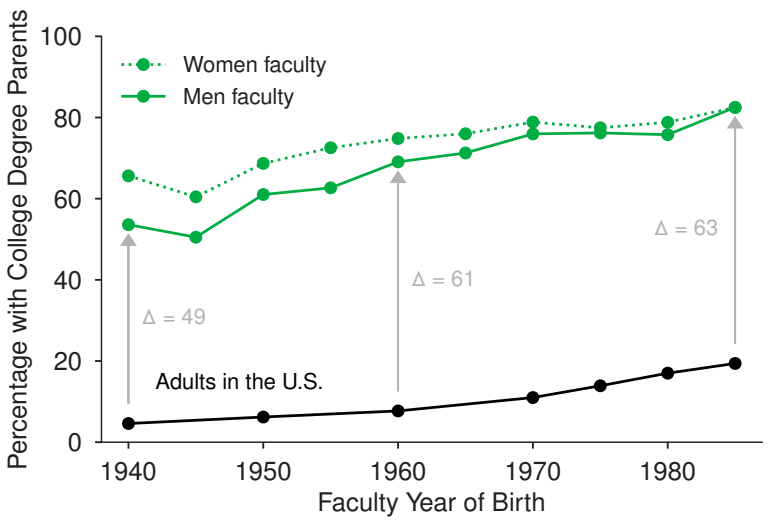

FIG. 2. Percentages of faculty with college educated parents by gender and across time. Percentages of faculty reporting their parents' highest level of education was at least a college degree by faculty year of birth (green), compared with the fraction of U.S. adults earning a college degree or higher in a given year (black). Gray arrows are the difference between men faculty and U.S. adult trends.
(U.S. Census and NSF SED) versus households. Across all eight fields, we estimate that faculty are on average between 12 to 25 times more likely to have a parent with a $\mathrm{PhD}$ than the general population, and about twice as likely as other individuals who hold a PhD (Fig. 1. SI C).

The distributions of parents' educational attainment are similar across the disciplines surveyed, suggesting that despite disciplinary differences in scholarship, funding, and culture, having a parent with a $\mathrm{PhD}$ is universally advantageous for becoming a professor. The rates at which parents of faculty have a college degree or higher have also slightly increased over time, which mirrors broader social trends in the U.S. population (Fig. 22. Women are particularly more likely to have highly educated mothers: $33.3 \%$ of women versus $28.3 \%$ of men have a mother who holds a graduate degree $(z=4.5$, $N=7107, p<0.001)$. Historically, rates of parents' college completion among women faculty is higher than men faculty; however, this gap has steadily closed over time fully reaching parity for faculty born in 1985 (Fig. 2).

\section{Academic Support}

We find that faculty with $\mathrm{PhD}$ parents are far more likely to receive support and encouragement for their academic careers from their parents (on a scale of 1 to 5 : 4.5 versus 3.9 for less than $\mathrm{PhD}, t=17.2, N=5725$, $p<0.001$ ), which is consistent with prior work 43 . This question came from an optional later section of the survey, but responses were a representative sample of the frame (SI A). In fact, the career support that faculty report receiving from their parents increases with greater parental education (Fig. 3) and does not depend on faculty gender (average rating of 4.0). This strong correlation between parental education and faculty career support suggests that the family resources and experiences of faculty with highly educated parents differ from those without highly educated parents and differ in ways that correlate with improving the odds that a person becomes a professor. For example, the degree of family support is 


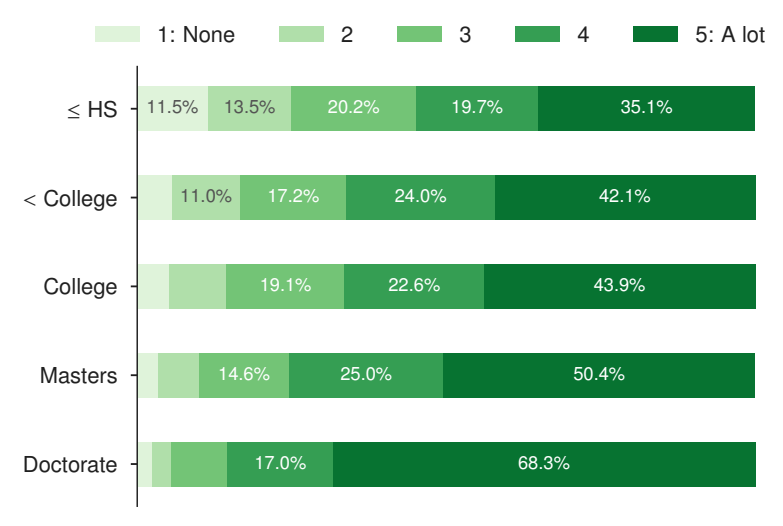

FIG. 3. Parental support by education level. Amount of support parents provided for academic careers on a scale of 1 (None at all) to 5 (A lot), stratified by faculty members' parents' highest education levels.

known to correlate with both undergraduate and graduate student retention [19, 44. Given what is known about educational stratification, we expect that there are other sociocultural mechanisms through which being the child of highly educated parents increases the chances of becoming faculty, such as greater identification with academic ideals, more and earlier experiences in activities valued by academia, or simply closer role models 45 .

\section{(Proxied) Parents' Income}

Faculty also tend to spend their childhoods in ZIP codes that are wealthier than the general public (Fig. 4). The median proxied household income based on ZIP code data for surveyed faculty when they were children is $23.6 \%$ higher than the median across all ZIP codes $(\$ 73 \mathrm{~K}$ versus $\$ 59 \mathrm{~K}$, Mann-Whitney $\mathrm{U}, \rho=0.4, N=1.2 \times 10^{8}$, $p<0.001)$. Consistent with the importance of parental education on faculty careers, proxied parental income is correlated with parental education: faculty who reported that at least one of their parents holds a college degree were associated with higher average proxied household incomes $(\$ 78 \mathrm{~K})$ than those who said their parents did not hold a college degree $(\$ 59 \mathrm{~K} ; \rho=0.3, N=3916$, $p<0.001)$. Across disciplines, median proxied parental income remains relatively high, ranging from $\$ 67 \mathrm{~K}$ (Sociology) to $\$ 78 \mathrm{~K}$ (History). Faculty are more likely to have grown up in urban areas compared to the geographic distribution of the U.S. population around the average year faculty were born $(89.6 \%$ versus $73.6 \%)$ [46. And the majority of faculty reported that their parents owned a home during the first 18 years of their life $(75.7 \%$ versus $13.4 \%$ said primarily rented, and $10.9 \%$ rented and owned equally), higher than one would expect given rates in the U.S. at the time ( $62 \%$ of homes owned by their occupants in 1960 [4]). Hence, faculty tend to come from families with relatively stable childhood financial circumstances.

\section{Impact of Parental Education on Becoming Faculty}

Because the educational attainment of parents is strongly correlated with becoming faculty, we can use data on how many $\mathrm{PhDs}$ are granted in a given year to forecast the changing composition of the professoriate. To better quantify this relationship, we model how the likelihood of having $\mathrm{PhD}$ parents depends on a scholar's characteristics.

Conditioned on having a parent with a $\mathrm{PhD}$, the probability of becoming a faculty member is given by:

$\operatorname{Pr}\left(\right.$ faculty $\left.\mid \begin{array}{c}\text { PhD } \\ \text { Parent }\end{array}\right)=\frac{\operatorname{Pr}\left(\begin{array}{c}\text { PhD } \\ \text { Parent }\end{array} \mid \text { faculty }\right) \operatorname{Pr}(\text { faculty })}{\operatorname{Pr}\left(\begin{array}{c}\text { PhD } \\ \text { Parent }\end{array}\right)}$

where our estimates of $\operatorname{Pr}(\mathrm{PhD}$ parent $/$ faculty $)$ and $\operatorname{Pr}(\mathrm{PhD}$ parent $)$ are given by the probability of faculty with $\mathrm{PhD}$ parents in our survey, and the probability of an adult having a $\mathrm{PhD}$ close to the birth year of a professor (22.2\% and $0.9 \%$ respectively, Table I). To estimate the probability of being a tenure-track faculty $\operatorname{Pr}$ (faculty), we assess the proportion of the U.S. adult workforce employed in postsecondary education recorded by the $\mathrm{Bu}-$ reau of Labor Statistics, around the year in which a professor started their job (0.4\%) [48. Because tenure track faculty are just one kind of employee in postsecondary education, this approach likely overestimates the percentage of the workforce employed as tenure-track faculty.

Combining these quantities, we estimate that the probability of becoming a faculty member given that one's parents hold a $\mathrm{PhD} \operatorname{Pr}$ (faculty $\mid \mathrm{PhD}$ parent) is $9.5 \%$, indicating a strong degree of both educational heritability and substantial professional advantage.

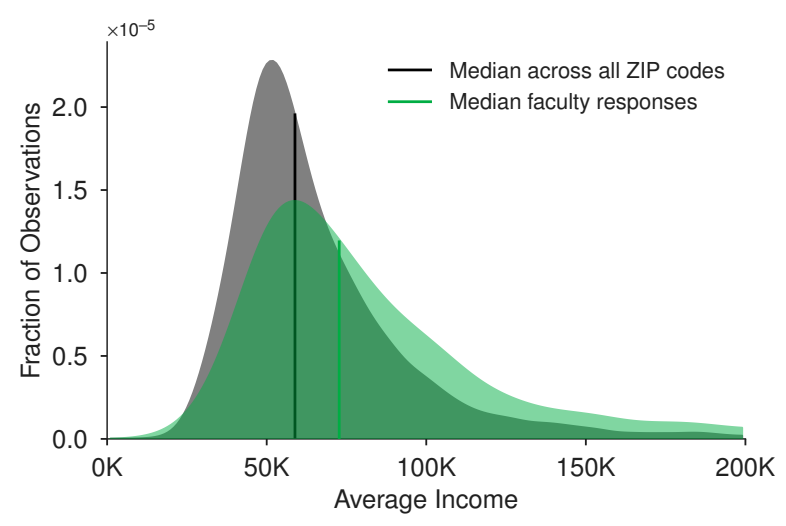

FIG. 4. Parental income distribution. Average income distribution estimated using faculty members' childhood ZIP codes (green), compared with the income distribution across the 1998 U.S. population (black). 

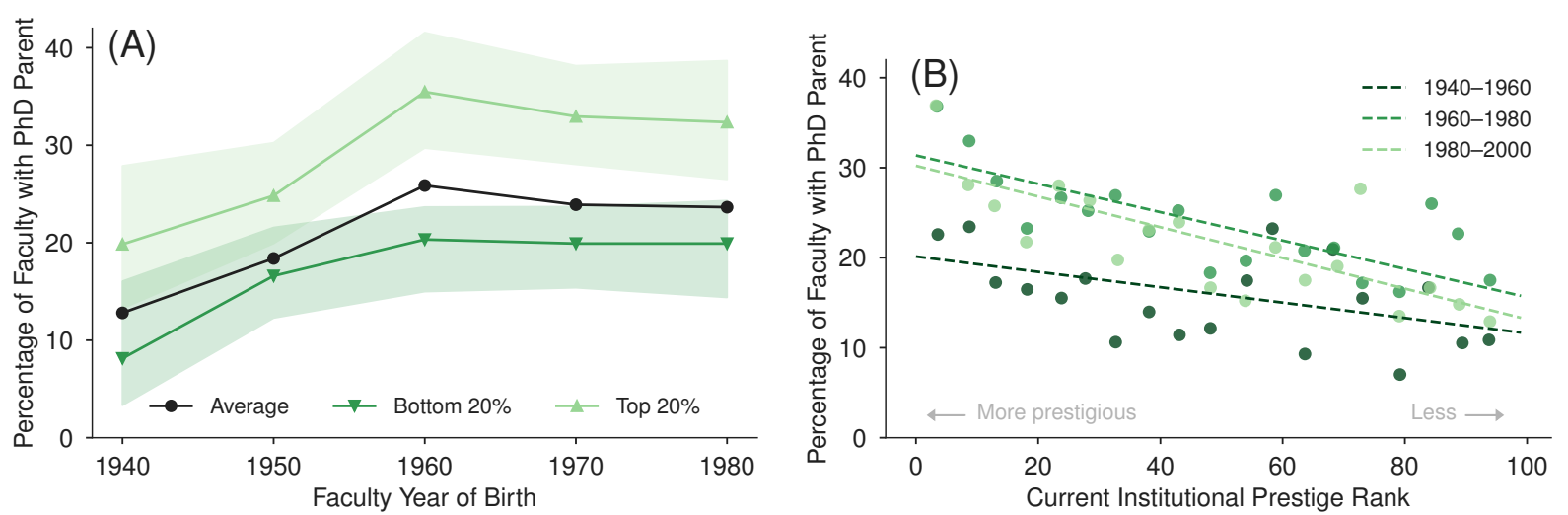

FIG. 5. Trends in the percentage of faculty with a PhD parent. (A) Percentage of faculty with at least one parent holding a PhD, stratified by prestige of the faculty's current institution. Green upward arrows describe faculty at top $20 \%$ of institutions by USNWR or NRC ranking, and downward triangles the bottom $20 \%$ of ranked institutions. Shaded regions denote empirical 95\% confidence intervals. The black line describes the average proportion of faculty with PhD parents. (B) The relationship between the current institutional ranking of faculty and whether they have a parent with a PhD. Lines show the relationship for faculty born in different time periods.

\section{Relationships with Sociodemographic Diversity}

To the extent that becoming a professor is strongly influenced by having parents with doctoral degrees, our results paint a disheartening picture for efforts to build a racially diverse pipeline to the professoriate. Broad social and educational inequality within the U.S. indicates that Black and Hispanic adults are less likely to hold graduate degrees of any kind compared to White adults (Fig. 6). Our race-independent estimate of the probability of becoming faculty may overestimate the production of Black or Hispanic faculty because it fails to account for the lower probability of $\mathrm{PhD}$ parents among Black and Hispanic children conditional on socioeconomic status. Obtaining a precise race-conditioned estimate would require additional conditional estimates that are not currently available (e.g., the proportion of Black and Hispanic people who obtain faculty positions).

However, we do find evidence of racial differences within our survey results: White professors are more likely to have a parent with a $\mathrm{PhD}(23.4 \%, N=5905)$ compared to Black or Hispanic faculty (17.2\% and $16.9 \%$ respectively, $N=518$ ). This distinction is even more pronounced among women surveyed, where $25.5 \%$ of White women have a $\mathrm{PhD}$ parent versus $14.6 \%$ of Black women (Table S3). To the extent that the probability of becoming faculty depends on parental education, and specifically on having $\mathrm{PhD}$ parents, this large racial gap in $\mathrm{PhD}$ attainment is an intergenerational impediment to the proportion of Black and Hispanic scholars who become tenure-track faculty.

The relationship between parents' education and the gender composition of the professoriate is complex. For instance, women in our sample are more likely to have $\mathrm{PhD}$ parents than are men (24.8\% versus $20.8 \%)$. Identifying the reasons underlying this pattern is an in-

\begin{tabular}{l|l|l|l} 
& Model I & Model II & Model III \\
\hline \hline Urban neighborhood & 0.129 & 0.552 & 0.914 \\
$(0.050)$ & $(0.052)$ & $(0.054)$ \\
\hline $\begin{array}{l}\text { Average neighborhood income } \\
\text { (standardized) }\end{array}$ & & $\begin{array}{l}-1.447^{*} \\
(0.037)\end{array}$ & $\begin{array}{l}-1.352^{*} \\
(0.038)\end{array}$ \\
\hline $\begin{array}{l}\text { Parents' highest degree: } \\
\text { Elementary }\end{array}$ & & & -2.946 \\
& & $(0.172)$ \\
Some high school & & -1.816 \\
& & & $(0.191)$ \\
High school & & $-4.873 *$ \\
& & $(0.065)$ \\
College & & & $-4.416 *$ \\
& & & $(0.063)$ \\
Masters & & & $-5.177 *$ \\
& & & $(0.059)$ \\
PhD & & $-6.889 *$ \\
& & & $(0.061)$ \\
\hline Adjusting for discipline, race / Yes & Yes & Yes \\
ethnicity, gender, PhD prestige & & & \\
\hline Adjusted $R^{2}$ & 0.105 & 0.107 & 0.109 \\
\hline \hline
\end{tabular}

TABLE II. Linear regression of current institutional prestige (ordinal ranking from 1 to 100) based on neighborhood, income, and parents' education levels, adjusting for discipline, race / ethnicity, gender, and $\mathrm{PhD}$ ranking. Bootstrapped standard errors in parentheses, and coefficients with $p<0.05$ are denoted by *. Baseline is women in Anthropology from urban neighborhoods whose parents' highest education was some college.

teresting direction for future work. Of course, socioeconomic status does not impede gender diversity in academia in the same way or to the extent that it does for racial diversity. Nevertheless, parents may differentially allocate resources to sons and daughters that influence their academic achievement [49. Moreover, the intersection between race and gender is not neutral with respect 
to the likelihood of becoming faculty. For example, Black women faculty are less likely to have $\mathrm{PhD}$ parents than Black men (Table S3). Prior evidence suggests that there has been a growing gender gap in college completion, with women outpacing men, among both White and, to a larger extent, Black Americans [50. The overrepresentation of Black men from educationally privileged families may imply a differential selection within academia, wherein Black men need more social capital to pursue these careers. Untangling how gender, race and social origins interconnect to shape who pursues academic careers, and specifically why Black women professors were less likely to come from more educationally privileged families, is an important direction for future research is an important direction of future research.

\section{Trends in Socioeconomic Origins}

Academia has undergone many dramatic shifts over the past 100 years, and our survey reveals several interesting and related trends. For instance, we find that the rate of faculty born from 1940-60 reporting that a parent holds a $\mathrm{PhD}$ has increased from $13 \%$ at the beginning of the period to $26 \%$ by the end (Fig. $5 \mathrm{~A}$ ), but then remains stable at above $20 \%$ across the next 50 years. This increase from 1940-60's mirrors the increasing college and graduate school enrollment rates within the U.S. over the same period [51, 52, and hence may simply reflect a general broadening of access to higher education. However, the subsequent stability of the rate at which faculty have a $\mathrm{PhD}$ parent, in contrast to the continuing growth in and diversifying demographics of doctoral degree attainment [53], suggests that the relationship between the educational attainment of faculty parents and the likelihood of becoming faculty has been consistent and strong for nearly half a century.

Parental education is so consequential that it also correlates with where in the academic hierarchy a professor lands. Across all years, we find that nearly a third of faculty at top-ranked universities across all eight fields report that one of their parents holds a $\mathrm{PhD}$, and faculty at these elite departments are $57.4 \%$ more likely to have a parent who holds a $\mathrm{PhD}$ than are faculty at the least prestigious departments $(29.8 \%$ versus $19.0 \% ; z=6.5$, $p<0.001, N=2612$ ). This concentration among elite departments is consistent with prior research documenting the ways academic hiring tends to devalue faculty of lower socioeconomic standing [26, 27, and advantage faculty from more privileged backgrounds.

\section{Modeling Faculty Placement}

Adjusting for faculty discipline, $\mathrm{PhD}$ prestige, race / ethnicity, and gender within a model, we find that faculty who had parents who attended college tend to be employed at significantly more prestigious universities than faculty without these childhood socioeconomic advantages (Table II). We recognize that $\mathrm{PhD}$ prestige may in fact be endogenous to this model of faculty placement because of $\mathrm{PhD}$ placement's likely relationship with parents education, but regardless include it as a control due to the strong evidence of its importance in predicting faculty placement [54]. Here, institutional prestige is defined by ordinal ranking, where the most prestigious universities have smaller rank (1), and less prestigious have larger rank (100). On average, faculty with a $\mathrm{PhD}$ parent move "up" in the institutional rankings by nearly 7 percentile ranks $(t=-3.4, N=2709, p=0.001)$. Faculty who grew up in wealthy neighborhoods, who are also less racially diverse than the general population, also tended to place at more prestigious institutions. Socioeconomic status may constrain an individual's search for a faculty job either by influencing which institutions they apply to, or by shaping their ability to stay on the academic track while searching for employment $(\mathrm{SI} D$. These results have direct implications for efforts to increase the socioeconomic and racial diversity of the professoriate, particularly at the most prestigious institutions that train most future professors [54. The higher-prestige placement of faculty from advantaged socioeconomic backgrounds also represents a structural barrier to the visibility of the ideas of lower socioeconomic status faculty because scientific discoveries made at more prestigious universities are more likely to spread throughout academia [55].

\section{Disadvantaged Socioeconomic Origins}

Despite the significant correlation between having a parent who holds a $\mathrm{PhD}$ and placement as faculty in the prestige hierarchy, not all faculty at elite universities (here: top $20 \%$ by USNWR or NRC) have this advantage. For elite faculty without PhD-holding parents, career support from colleagues both within and beyond their institution, and the wealth and urbanicity of their childhood ZIP all become more important factors in explaining their placement at an elite institution. Faculty without $\mathrm{PhD}$ parents who are employed at prestigious institutions report slightly higher levels of support from colleagues compared to those at lower ranked institutions both within their institution (4.0 versus $3.8 ; t=3.6$, $N=4,449, p<0.001)$, and outside their institution (4.0 versus $3.9 ; t=2.6, N=4,448, p=0.009$ ).

Most faculty earned their $\mathrm{PhDs}$ at elite institutions 54. Faculty without a PhD parent, currently employed at an elite university, were more likely to come from more elite $\mathrm{PhD}$ programs than were similar faculty at non-elite universities (9.8 versus 21.1; Mann-Whitney $\mathrm{U}, \rho=0.4, N=3813, p<0.001)$. Furthermore, without $\mathrm{PhD}$ parents, faculty at the top institutions are more likely to come from urban neighborhoods $(92.3 \%$ versus $87.3 \%)$ that are higher income $(\$ 104 \mathrm{~K}$ versus $\$ 89 \mathrm{~K}$; Mann-Whitney $\mathrm{U}, \rho=0.4, N=2974, p<0.001)$. 


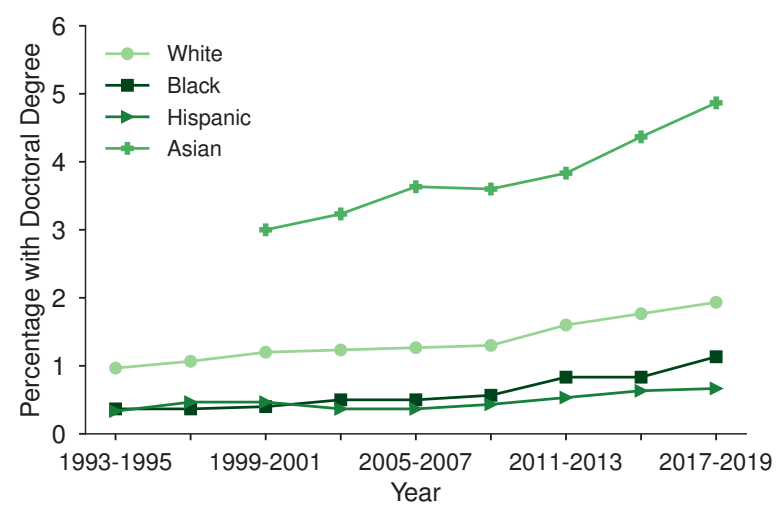

FIG. 6. PhD attainment by racial or ethnic group. Percentages of White, Black, Hispanic, and Asian adults (at least 25 years old) in the United States population that hold doctorate degrees [56]. Trend are smoothed with averages every three years.

\section{CONCLUSION}

Using a large survey of eight academic disciplines spanning STEM, social science, and the humanities, we quantify the extent to which becoming a professor is associated with indicators of socioeconomic status, and in particular is most accessible to the children of doctoral recipients and those who grew up in wealthy urban neighborhoods. Considering the intersection between race and class, we conclude that this dependence on parent educational education and SES likely limits racial diversity within the professoriate.

To summarize, nearly a quarter $(22.2 \%)$ of faculty reported that one of their parents holds a $\mathrm{PhD}$, and over half $(51.8 \%)$ had a parent who holds a graduate degree, compared to less than $10 \%$ of U.S. adults of similar ages (Table I). Faculty who have parents with PhDs report receiving more support from them for their careers (Fig. 3) and are more likely to be employed at elite institutions. Nearly a third of faculty at top ranked universities report that their parent holds a $\mathrm{PhD}(29.5 \%)$, versus a fifth $(19.2 \%)$ at lower ranked institutions. This pattern represents a significant source of social reproduction at the highest levels of academic attainment. Moreover, given broader racial inequality in educational attainment, academia's overrepresentation of inherited advantages represents a fundamental constraint to increasing its racial diversity (Fig. 6).

Previous studies of childhood socioeconomic status of faculty have often been limited in scope, due to relatively small surveys of faculty or a lack of historical data on indicators of SES in the broader U.S., both of which were necessary for this study. Given the well-established correlations between household parental income and child educational attainment and patterns of micro-class reproduction in other economic sectors, the overrepresentation of faculty with $\mathrm{PhD}$ parents is perhaps unsurprising. Yet our results quantify just how large, and how persistent, that overrepresentation is.

In fact, the importance of having $\mathrm{PhD}$ parents appears so great that the rate of having them nearly doubles across the transition from completing a $\mathrm{PhD}$ to obtaining a faculty job (11.8\% versus $22.2 \%$; Table I). This effect indicates a substantial loss of talent in the pipeline from $\mathrm{PhD}$ to the transition to a faculty job. Doctoral students with $\mathrm{PhD}$ parents may be better prepared for the difficulties of the academic job market, which may confer an advantage that becomes even greater during periods when academic jobs are scarce, e.g., during a pandemic or a recession. Furthermore, the stability of this pattern across STEM fields, the social sciences, and humanities suggests that the loss of talent at this stage in the pipeline is unlikely to be caused by the existence of attractive non-academic jobs for STEM PhDs. Understanding the causes of this pattern is an important direction for future work.

But the even greater overrepresentation of faculty with $\mathrm{PhD}$ parents at the most prestigious institutions (Fig. 5) implies that increasing sociodemographic diversity in academia is not only a pipeline problem. Indeed, our findings complement research that suggests a reemergence of socioeconomic reproduction at the highest levels of educational attainment 8, 57. Progress towards broadening participation in science will remain limited if our current practices within academia favor individuals with advantages conferred by parental socioeconomic and occupational privilege [21, 26, 27.

Socioeconomic background plays a critical role in shaping academic success, from secondary school to reaching the ranks of tenure-track faculty positions. Social and cultural factors also play a role [58, such as the cultural value of academic success (which Fig. 3 suggests can involve intergenerational transmission), effective role models, or even access to scholarly advice or opportunities from parents who understand how academia works. $\mathrm{PhD}$ parents are uniquely positioned to offer guidance and support in children's postsecondary studies, through the graduate application process, negotiating admissions offers, progress in graduate programs, and job market success. For example, within our study, faculty who had a $\mathrm{PhD}$ parent also earned their $\mathrm{PhDs}$ at slightly more elite institutions (7.1 versus 11.6; Mann-Whitney U, $\rho=0.4$, $N=4906, p<0.001$ ), and earning a $\mathrm{PhD}$ at an elite institution contributes towards upward academic mobility [59. This finding suggests that PhD parents' deep understanding of these processes facilitates micro-class reproduction. The overall socioeconomic composition of faculty is likely shaped by several complex, interacting factors, and a full explanation of the patterns will require a careful accounting of each in future work.

The interpretation of our work is limited by the granularity of the IRS and Census data we link to individual responses, and the current composition of tenure-track faculty. Several of our comparisons rely on aggregated measures used to proxy for income based on respon- 
dents' childhood ZIP code. Many ZIP code boundaries have changed over time and may span heterogenous populations 60. Each of these may limit the accuracy of our childhood income measures, especially for older faculty. In future work, better estimates of household income could be obtained from information on respondents' childhood Census blocks, or from de-identified historical tax records 61. Similarly, our analyses of race and ethnicity are limited by the use of the 2010 Census classification standard, which provides some consistency with 2020 standards 62], but precludes certain more fine-grained analyses.

Furthermore, our survey was restricted to current tenure-track faculty at research intensive academic institutions between 2017 and 2020. As a result, our data say little about contingent faculty at these institutions, which represent an increasing fraction of university instructional staff 63. We also do not know how gender discrimination, racism, or classism impacts academics' intentions to persist, and we do not observe faculty who left academia prior to our survey date, whether that was after graduate school, a postdoctoral position, or a contingent or tenure-track academic position, and whether that is due to feeling pulled towards more desirable opportunities outside of academia or pushed out by discrimination in hiring or promotion within. This group may be a population biased toward faculty from lowerincome backgrounds [19]. Such a bias would tend to lead us to underestimate the observed associations or importance of socioeconomic status in our analyses if we aimed to examine associations for all faculty entering academia, but these associations do not bias our estimates for current faculty. An important and complementary direction of future work would examine socioeconomic status among non-tenure track faculty and investigate its role in recruitment and retention before and along the tenure track.

While this work highlights the advantages that SES may confer for becoming and remaining faculty, it does not explicitly speak to the social or professional difficulties that underrepresented individuals experience stemming from their gender, race, ethnicity, or socioeconomic status once they become faculty. For example, women are less likely to be viewed as competent [64, 65, less likely to be awarded for their research 66], less likely to be invited for talks 67, and less likely to be compensated fairly [68, 69]. Black faculty earn less despite no measurable differences in productivity [70] and may have their research evaluated less positively [31, all while facing unequal service burdens and racism on and off campus [71, 72]. While research on how socioeconomic status shapes faculty careers is less comprehensive, work generally points to less supportive environments [24, 25] and differences in research or teaching appointments [73. Individuals with disadvantaged socioeconomic origins may become faculty and still have greater difficulty navigating and finding support within academia.
Future research should consider why the importance of family background varies moderately by gender and across fields. In our survey, women are more likely to have a parent with a college degree or higher than men (Table S2), indicating the greater barriers facing women in reaching the highest ranks of academia. The reasons for this difference among tenure-track faculty require more investigation. Percentages of faculty with a $\mathrm{PhD}$ parent are lowest among Business and Sociology (17.3\%), and highest among Computer Science and History (26.3\%, $\left.\chi^{2}=39.1, N=3362, p<0.001\right)$. Compared to the educational attainment of professors' parents (Table I), and generally consistent with the result presented here, a survey of lawyers found about $12 \%$ of lawyers were the children of lawyers 74, and among doctors in Sweden, $20 \%$ of physicians were the children of physicians [75]. Whether or not having a $\mathrm{PhD}$ parent provides more of an advantage to academic faculty than one would expect relative to other high status occupations is an important question for future research.

Our study's detailed and cross-disciplinary view of the deep socioeconomic roots of current U.S. faculty highlights the social reproduction of the highest levels of academic attainment and scientific influence. These results raise a critical question regarding what ramifications high SES overrepresentation in the academic workforce - and its skewed intersection with race and class in the U.S. - have on the type of scholarship that faculty produce and on the scholars they train. That is, what discoveries are not made and what ideas are not developed as a result of academia's historical and current lack of socioeconomic diversity? A lack of diversity is already known to reduce research on public health disparities 31, immigration, mental health, and gender-based discrimination [29]. However, it is likely that the loss of useful research is more pervasive, because the relationship between researcher identity and scholarship is complex, depending not only on scientific social capital 76 but also on how that capital can be invested. Developing a quantitative understanding of how representational diversity shapes scholarship across fields is an important direction of future work, which will rely on quantitative assessments of current diversity and its roots like the one provided here. Making academia more diverse and inclusive is a considerable challenge, given the complex interplay of SES and academic achievement from early schooling through academic appointments. Progress in this direction, however, is likely to produce substantial scientific and societal benefits.

\section{ACKNOWLEDGEMENTS}

The authors thank Eliana Colunga, Brian Donovan, Bailey Fosdick, Tamia Harris-Tryon, Herrissa Lamothe, Robert Manduca, Jaymes Pyne, Seth Spielman, Katherine Spoon, Jeremy Van Cleve, and Samuel Way for 
helpful comments, and all survey participants for providing their valuable opinions and time.

Funding: This work was supported in part by National Science Foundation Award SMA 1633791 (ACM, AC, DBL, MG), Air Force Office of Scientific Research Award FA9550-19-1-0329 (AC, DBL, MG, NL), National Science Foundation Graduate Research Fellowship Award DGE 1650115 (ACM). JEB benefited from facilities and resources provided by the California Center for Population Research at UCLA (CCPR), which receives core support (P2C-HD041022) from the Eunice Kennedy Shriver National Institute of Child Health and Human Development (NICHD).

Author contributions: ACM and AC devised analysis, and ACM, AC, and JEB wrote the manuscript. MG, AC, DBL, ACM, and NL designed and conducted the survey. MG, NL, and ACM collected data and performed data validation. ACM and NL analyzed data. All authors finalized the manuscript.

Competing interests: None.

\section{CITATION DIVERSITY STATEMENT}

Recent work in several fields of science has identified a bias in citation practices such that papers from women and other minority scholars are under-cited relative to the number of such papers in the field 77 81]. Here we sought to proactively consider choosing references that reflect the diversity of the field in thought, form of contribution, gender, race, ethnicity, and other factors. First, we obtained the predicted gender of the first and last author of each reference by using databases that store the probability of a first name being carried by a woman [81, 82. By this measure (and excluding self-citations to the first and last authors of our current paper), our references contain $27.8 \%$ woman(first)/woman(last), $9.5 \%$ man/woman, $16.6 \%$ woman/man, and $46.1 \%$ man $/$ man. This method is limited in that a) names, pronouns, and social media profiles used to construct the databases may not, in every case, be indicative of gender identity and b) it cannot account for intersex, non-binary, or transgender people. Second, we obtained predicted racial/ethnic category of the first and last author of each reference by databases that store the probability of a first and last name being carried by an author of color [83, 84. By this measure (and excluding selfcitations), our references contain $10.8 \%$ author of color (first)/author of color(last), $16.5 \%$ white author/author of color, $14.3 \%$ author of color/white author, and $58.4 \%$ white author/white author. This method is limited in that a) the names and Florida Voter Data used to make the predictions may not be indicative of racial/ethnic identity, and b) it cannot account for Indigenous and mixed-race authors, or those who may face differential biases due to the ambiguous racialization or ethnicization of their names. We look forward to future work that could help us to better understand how to support equitable practices in science.
[1] Catherine Riegle-Crumb, Barbara King, and Yasmiyn Irizarry. Does STEM Stand Out? Examining Racial/Ethnic Gaps in Persistence Across Postsecondary Fields. Educational Researcher, 48(3):133-144, 2019.

[2] Poppy Lauretta McLeod, Sharon Alisa Lobel, and Taylor H Cox Jr. Ethnic Diversity and Creativity in Small Groups. Small Group Res., 27(2):248-264, 1996.

[3] Jeffrey F Milem. The educational benefits of diversity: Evidence from multiple sectors. In Mitchel J Chang, Daria Witt, James Jones, and Kenji Hakuta, editors, Compelling Interest: Examining the evidence on racial dynamics in higher education, pages 126-169. Stanford University Press, 2003.

[4] Peter M. Blau and Otis Dudley Duncan. The American Occupational Structure. John Wiley \& Sons, Inc., New York, 1967.

[5] Michael Hout and Alexander Janus. Educational mobility in the United States since the 1930s. In Greg J. Duncan and Richard J. Murnane, editors, Whither Opportunity? Rising Inequality, Schools, and Children?s Life Chances, pages 165-186. Russell Sage Foundation, New York, 2011.

[6] Martha Bailey and Sue Dynarski. Inequality in postsecondary education. In Greg J. Duncan and
Richard J. Murnane, editors, Whither Opportunity? Rising Inequality, Schools, and Children?s Life Chances, pages 117-132. Russell Sage Foundation, New York, 2011.

[7] Deidre Bloome, Shauna Dyer, and Xiang Zhou. Educational inequality, educational expansion, and intergenerational income persistence in the United States. American Sociological Review, 83:1215-1253, 2018.

[8] Florencia Torche. Is a College Degree Still the Great Equalizer? Intergenerational Mobility across Levels of Schooling in the United States. American Journal of Sociology, 117(3):763-807, 2011.

[9] Amanda E. Lewis amd John B. Diamond. Despite the Best Intentions: How Racial Inequality Thrives in Good Schools. Oxford University Press, 2015.

[10] Annette Lareau. Unequal Childhoods: Class, Race, and Family Life. University of California Press, 2011.

[11] Jessica McCrory Calarco. Coached for the classroom: Parents' cultural transmission and children's reproduction of educational inequalities. American Sociological Review, 79(5):1015-1037, 2014.

[12] Samuel Bowles and Herbert Gintis. Schooling in Capitalist America: Educational Reform and the Contradictions of Economic Life. Basic Books, New York, 1976. 
[13] Jonathon Kozol. Savage Inequalities. Harper Perennial, 1991.

[14] Raj Chetty and Nathanial Hendren. The impacts of neighborhoods on intergenerational mobility I: Childhood exposure effects. Quarterly Journal of Economics, 133:1107-1162, 2018.

[15] Raj Chetty, John N Friedman, Emmanuel Saez, Nicholas Turner, and Danny Yagan. Mobility report cards: The role of colleges in intergenerational mobility. Technical report, National Bureau of Economic Research, 2017.

[16] Anthony Abraham Jack. The privileged poor: How elite colleges are failing disadvantaged students. Harvard University Press, 2019.

[17] Elizabeth Armstrong and Laura Hamilton. Paying for the Party: How College Maintains Inequality. Harvard University Press, 2015.

[18] Ann L. Mullen, Kimberly A. Goyette, and Joseph A. Soares. Who Goes to Graduate School? Social and Academic Correlates of Educational Continuation after College. Sociology of Education, 76(2):143-169, 2003.

[19] Susan K Gardner and Karri A Holley. "Those invisible barriers are real": The progression of first-generation students through doctoral education. Equity \& Excellence in Education, 44(1):77-92, 2011.

[20] Julie R Posselt and Eric Grodsky. Graduate Education and Social Stratification. Annual Review of Sociology, 43:353-378, 2017.

[21] Pierre Bourdieu. Distinction: A social critique of the judgement of taste. Harvard University Press, 1984.

[22] Kim A Weeden and David B Grusky. The three worlds of inequality. American Journal of Sociology, 117(6):17231785, 2012.

[23] Martin J Finkelstein, Martin J Finkelstein, Robert K Seal, and Jack H Schuster. The new academic generation: A profession in transformation. JHU Press, 1998.

[24] Timothy J Haney. Factory to faculty: Socioeconomic difference and the educational experiences of university professors. Canadian Review of Sociology/Revue canadienne de sociologie, 52(2):160-186, 2015.

[25] Bea Waterfield, Brenda L Beagan, and Tameera Mohamed. "You Always Remain Slightly an Outsider": Workplace Experiences of Academics from WorkingClass or Impoverished backgrounds. Canadian Review of Sociology/Revue canadienne de sociologie, 56(3):368388, 2019.

[26] Damani K White-Lewis. The facade of fit in faculty search processes. The Journal of Higher Education, 91(6):833-857, 2020.

[27] Lynn Arner. Working-class women at the mla interview. Rhizomes: Cultural Studies in Emerging Knowledge, 27, 2014.

[28] Scott E Page. The Difference: How the Power of Diversity Creates Better Groups, Firms, Schools, and Societies. Princeton University Press, 2008.

[29] Diego Kozlowski, Vincent Larivière, Cassidy R Sugimoto, and Thema Monroe-White. Intersectional inequalities in science. Proceedings of the National Academy of Sciences, 119(2), 2022.

[30] Bas Hofstra, Vivek V Kulkarni, Sebastian Munoz-Najar Galvez, Bryan He, Dan Jurafsky, and Daniel A McFarland. The diversity-innovation paradox in science. Proceedings of the National Academy of Sciences, 117(17):9284-9291, 2020.
[31] Travis A Hoppe, Aviva Litovitz, Kristine A Willis, Rebecca A Meseroll, Matthew J Perkins, B Ian Hutchins, Alison F Davis, Michael S Lauer, Hannah A Valantine, James M Anderson, et al. Topic choice contributes to the lower rate of NIH awards to African-American/black scientists. Science Advances, 5(10):eaaw7238, 2019.

[32] Jennifer Dykema, John Stevenson, Lisa Klein, Yujin Kim, and Brendan Day. Effects of E-Mailed Versus Mailed Invitations and Incentives on Response Rates, Data Quality, and Costs in a Web Survey of University Faculty. Social Science Computer Review, 31(3):359-370, 2013.

[33] Morgan M. Millar and Don A. Dillman. Improving Response to Web and Mixed-Mode Surveys. Public Opinion Quarterly, 75(2):249-269, 052011.

[34] Dongbin Kim, Lisa Wolf-Wendel, and Susan Twombly. International faculty: Experiences of academic life and productivity in US universities. The Journal of Higher Education, 82(6):720-747, 2011.

[35] U.S. Census Bureau. Table 4. Years of School Completed By Persons 25 Years Old and Over, By Race, For The United States, By Regions. U.S. Department of Commerce, March 1967.

[36] National Science Foundation. Doctorate Recipients from US Universities: 2018. National Center for Science and Engineering Statistics, 2019.

[37] Lori Thurgood, Mary J Golladay, and Susan T Hill. Us doctorates in the 20th century. Arlington, VA: National Science Foundation, Division of Science Resources Statistics, 2006.

[38] Robert Kominski and Paul M Siegel. Measuring education in the current population survey. Monthly Lab. Rev., 116:34, 1993.

[39] Nancy Krieger. Overcoming the absence of socioeconomic data in medical records: validation and application of a census-based methodology. American journal of public health, 82(5):703-710, 1992.

[40] Nancy Krieger, David R Williams, and Nancy E Moss. Measuring social class in us public health research: concepts, methodologies, and guidelines. Annual review of public health, 18(1):341-378, 1997.

[41] Arline T Geronimus, John Bound, and Lisa J Neidert. On the validity of using census geocode characteristics to proxy individual socioeconomic characteristics. Journal of the American Statistical Association, 91(434):529-537, 1996.

[42] Steven Manson, Jonathan Schroeder, David Van Riper, Tracy Kugler, and Steven Ruggles. Ipums national historical geographic information system, 2020.

[43] Patrick T Terenzini, Leonard Springer, Patricia M Yaeger, Ernest T Pascarella, and Amaury Nora. Firstgeneration college students: Characteristics, experiences, and cognitive development. Research in Higher education, 37(1):1-22, 1996.

[44] Dollean C York-Anderson and Sharon L Bowman. Assessing the college knowledge of first-generation and second-generation college students. Journal of College Student Development, 1991.

[45] Alex Bell, Raj Chetty, Xavier Jaravel, Neviana Petkova, and John Van Reenen. Who becomes an inventor in America? The importance of exposure to innovation. The Quarterly Journal of Economics, 134(2):647-713, $20 \overline{19 .}$

[46] U.S. Census Bureau. Table 10. Population by Urban and Rural: Earliest Census to 2010. U.S. Department of Commerce, 2010. 
[47] Susan Wachter and Arthur Acolin. Owning or renting in the us: Shifting dynamics of the housing market. Penn IUR Brief (Philadelphia, PA: Penn Institute for Urban Research, 2016.

[48] Bureau of Labor Statistics. Occupational employment and wages. U.S. Department of Labor, 2000.

[49] Claudia Buchmann, Thomas A DiPrete, and Anne McDaniel. Gender inequalities in education. Annu. Rev. Sociol, 34:319-337, 2008.

[50] Anne McDaniel, Thomas A DiPrete, Claudia Buchmann, and Uri Shwed. The black gender gap in educational attainment: Historical trends and racial comparisons. Demography, 48(3):889-914, 2011.

[51] Claudia Goldin. America's graduation from high school: The evolution and spread of secondary schooling in the twentieth century. The Journal of Economic History, 58(2):345-374, 1998.

[52] Claudia Goldin and Lawrence F Katz. The shaping of higher education: The formative years in the united states, 1890 to 1940. Journal of Economic Perspectives, 13(1):37-62, 1999.

[53] Michael Offerman. Profile of the nontraditional doctoral degree student. New Directions for Adult and Continuing Education, 2011(129):21-30, 2011.

[54] Aaron Clauset, Samuel Arbesman, and Daniel B Larremore. Systematic inequality and hierarchy in faculty hiring networks. Science advances, 1(1):e1400005, 2015.

[55] Allison C Morgan, Dimitrios J Economou, Samuel F Way, and Aaron Clauset. Prestige drives epistemic inequality in the diffusion of scientific ideas. EPJ Data Science, 7(1):40, 2018

[56] U.S. Census Bureau. Table 3. detailed years of school completed by people 25 years and over by sex, age groups, race and hispanic origin: 2010. U.S. Department of Commerce, 2010.

[57] Florencia Torche. Intergenerational Mobility at the Top of the Educational Distribution. Sociology of Education, 91(4):266-289, 2018.

[58] Nicole M Stephens, Hazel Rose Markus, and Stephanie A Fryberg. Social class disparities in health and education: Reducing inequality by applying a sociocultural self model of behavior. Psychological review, 119(4):723, 2012.

[59] Samuel F Way, Allison C Morgan, Daniel B Larremore, and Aaron Clauset. Productivity, prominence, and the effects of academic environment. Proceedings of the National Academy of Sciences, 116(22):10729-10733, 2019.

[60] Tony H Grubesic. Zip codes and spatial analysis: Problems and prospects. Socio-economic planning sciences, 42(2):129-149, 2008.

[61] Raj Chetty, David Grusky, Maximilian Hell, Nathaniel Hendren, Robert Manduca, and Jimmy Narang. The fading american dream: Trends in absolute income mobility since 1940. Science, 356(6336):398-406, 2017.

[62] Carolyn A. Liebler, Sonya R. Porter, Leticia E. Fernandez, James M. Noon, and Sharon R. Ennis. America's churning races: race and ethnicity response changes between Census 2000 and the 2010 Census. Demography, 54(1):259-284, 2017.

[63] American Association of University Professors. Background Facts on Contingent Faculty Positions, 2017.

[64] Dakota Murray, Clara Boothby, Huimeng Zhao, Vanessa Minik, Nicolas Bérubé, Vincent Larivière, and Cassidy R
Sugimoto. Exploring the personal and professional factors associated with student evaluations of tenure-track faculty. PLOS One, 15(6):e0233515, 2020.

[65] Lauren A Rivera and András Tilcsik. Scaling down inequality: Rating scales, gender bias, and the architecture of evaluation. American Sociological Review, 84(2):248 274, 2019.

[66] Anne E Lincoln, Stephanie Pincus, Janet Bandows Koster, and Phoebe S Leboy. The Matilda Effect in science: Awards and prizes in the US, 1990s and 2000s. Social Studies of Science, 42(2):307-320, 2012.

[67] Christine L Nittrouer, Michelle R Hebl, Leslie AshburnNardo, Rachel CE Trump-Steele, David M Lane, and Virginia Valian. Gender disparities in colloquium speakers at top universities. Proceedings of the National Academy of Sciences, 115(1):104-108, 2018.

[68] Virginia Valian. Why so slow?: The advancement of women. MIT press, 1999.

[69] Debra A Barbezat and James W Hughes. Salary structure effects and the gender pay gap in academia. Research in Higher Education, 46(6):621-640, 2005.

[70] Robert A Thomson Jr, Esmeralda Sánchez Salazar, and Elaine Howard Ecklund. The very ivory tower: pathways reproducing racial-ethnic stratification in us academic science. Ethnic and Racial Studies, pages 1-21, 2020.

[71] NA Lewis Jr. What I've learned about being a Black scientist. Science, 16(6), 2020.

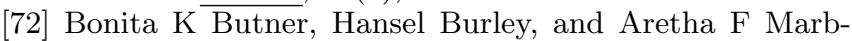
ley. Coping with the Unexpected: Black faculty at Predominately White Institutions. Journal of Black Studies, 30(3):453-462, 2000.

[73] Klara M Wanelik, Joanne S Griffin, Megan L Head, Fiona C Ingleby, and Zenobia Lewis. Breaking barriers? Ethnicity and socioeconomic background impact on early career progression in the fields of ecology and evolution. Ecology and Evolution, 2020.

[74] Ronit Dinovitzer. After the JD: First results of a National Study of Legal Careers. NALP Foundation for Law Career Research and Education, 2004.

[75] Maria Polyakova, Petra Persson, Katja Hofmann, and Anupam B Jena. Does medicine run in the family?evidence from three generations of physicians in sweden: retrospective observational study. bmj, 371, 2020.

[76] Pierre Bourdieu. The specificity of the scientific field and the social conditions of the progress of reason. Social science information, 14(6):19-47, 1975.

[77] Sara McLaughlin Mitchell, Samantha Lange, and Holly Brus. Gendered citation patterns in international relations journals. International Studies Perspectives, 14(4):485-492, 2013.

[78] Michelle L Dion, Jane Lawrence Sumner, and Sara McLaughlin Mitchell. Gendered citation patterns across political science and social science methodology fields. Political Analysis, 26(3):312-327, 2018.

[79] Neven Caplar, Sandro Tacchella, and Simon Birrer. Quantitative evaluation of gender bias in astronomical publications from citation counts. Nature Astronomy, 1(6):1-5, 2017.

[80] Daniel Maliniak, Ryan Powers, and Barbara F Walter. The gender citation gap in international relations. International Organization, 67(4):889-922, 2013.

[81] Jordan D Dworkin, Kristin A Linn, Erin G Teich, Perry Zurn, Russell T Shinohara, and Danielle S Bassett. The 
extent and drivers of gender imbalance in neuroscience reference lists. Nature neuroscience, 23(8):918-926, 2020.

[82] Dale Zhou, Eli J Cornblath, Jennifer Stiso, Erin G Teich, Jordan D Dworkin, Ann S Blevins, and Danielle S Bassett. Gender diversity statement and code notebook v1. 0. Zenodo, 2020.

[83] Anurag Ambekar, Charles Ward, Jahangir Mohammed, Swapna Male, and Steven Skiena. Name-ethnicity classification from open sources. In Proceedings of the 15th ACM SIGKDD international conference on Knowledge Discovery and Data Mining, pages 49-58, 2009.

[84] Gaurav Sood and Suriyan Laohaprapanon. Predicting race and ethnicity from the sequence of characters in a name. arXiv preprint arXiv:1805.02109, 2018.

[85] Allison C Morgan, Samuel F Way, and Aaron Clauset. Automatically assembling a full census of an academic field. PloS ONE, 13(8), 2018.

[86] Internal Revenue Service. SOI Tax Stats-Individual Income Tax Statistics-Zip Code Data (SOI), 2019.

[87] Internal Revenue Service. SOI Tax Stats-County Data, 2020.

[88] Internal Revenue Service. SOI Tax Stats Archive-1954 to 1999 Individual Income Tax Return Reports, 1999.

[89] Christine R Schwartz and Robert D Mare. Trends in educational assortative marriage from 1940 to 2003. Demography, 42(4):621-646, 2005.

[90] Øystein Kravdal and Ronald R Rindfuss. Changing relationships between education and fertility: A study of women and men born 1940 to 1964. American Sociological Review, 73(5):854-873, 2008.

\section{SUPPLEMENTARY MATERIALS}

\section{A. Survey Details}

Our survey was conducted over three years, from Summer 2017 to Fall 2020. The sample frame was assembled by drawing a set of $\mathrm{PhD}$-granting departments from the lists maintained by the U.S. News \& World Report for history and business, and the Computing Research Association for computer science, as in Ref. 54. The sample frames for Anthropology, Biology, History, Physics/Astronomy, Psychology, and Sociology are based on a comprehensive database of employment records for tenure-track faculty at U.S. PhD granting institutions that Academic Analytics-the academic consultancy that collected and maintains these faculty records provided for this research. Then, email addresses listed in online public directories were collected for faculty in our sample frame using both automated methods and Mechanical Turk [54, 85].

Each individual received one email reminder. All participants were included in a drawing for a cash lottery. Amounts varied by survey wave: one $\$ 1,000$ payment for Computer Science, $\$ 500$ for Business and History faculty, $\$ 500$ for Anthropology, Physics / Astronomy, Psychology, and Sociology faculty, and $\$ 250$ for Biology faculty. To reduce the burden on participants, our survey was divided into two parts. The first part took 1-2 minutes to complete and asked the most important questions of interest for our study, including participants' year of birth, childhood ZIP code, and information on their parents' education and employment. After completing the first part, participants were told that they can continue to the second part, which asked about parental support for their careers. Our study was approved by the University of Colorado Boulder Institutional Review Board.

In total, 8,009 faculty responded to our survey (out of 46692 surveyed; $17.2 \%$ ). Of those, 7,204 faculty provided information on a parent's level of highest education (89.9\% of respondents) and 4,807 provided the ZIP code in which they grew up (60.0\%). If a zip code was not provided, an open text box to specify city, state, and / or country was available. Overall, our response rate mirrors other online surveys with email invitations conducted in the context of academia [32, 33. Faculty that provided either parents' education or zip code for our analysis are generally representative with respect to their populations. Women responded at slightly higher rates than expected (Table S1), which may imply a slight upward bias in our results in parents' education. In our sample, women are somewhat more likely to come from highly educated families (one of their parents holds a $\mathrm{PhD}: 24.8 \%$ versus $20.8 \% ; z=3.9, N=7,145, p<0.001)$. Respondents came from 2,494 unique ZIP codes across the U.S. (Fig. S1). Most ZIP codes were represented by only one respondent (76.9\%). Questions about degree of parental support were asked towards the end of the survey $(85.9 \%$ of respondents). Those respondents had similar demo- 


\begin{tabular}{|c|c|c|c|c|c|c|c|c|c|c|}
\hline Field & & Men & Women & Nonbinary & Undisclosed & Assistant & Associate & Full & Prestige & $\mathrm{N}$ \\
\hline \multirow[t]{2}{*}{ Anthropology } & Respondents & 48.7 & $\overline{50.1}$ & 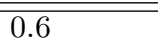 & $\overline{0.6}$ & 17.4 & $\overline{30.6}$ & $\overline{52.1}$ & $26.5(21.5)^{*}$ & 355 \\
\hline & Population & 50.8 & 49.2 & - & - & 21.1 & 32.1 & 46.7 & $22.6(19.4)$ & 1994 \\
\hline \multirow[t]{2}{*}{$\overline{\text { Biology }}$} & Respondents & $65.1^{*}$ & $34.3^{*}$ & 0.1 & 0.4 & $12.7^{*}$ & $29.7^{*}$ & $57.7^{*}$ & $83.3(61.4)$ & 1549 \\
\hline & Population & 70.1 & 29.9 & - & - & 23.1 & 27.6 & 49.3 & $83.2(64.5)$ & 10145 \\
\hline \multirow[t]{2}{*}{$\overline{\text { Business }}$} & Respondents & $66.7^{*}$ & $32.4^{*}$ & 0.1 & 0.8 & 30.8 & 25.7 & 43.5 & $42.4(27.5)$ & 1293 \\
\hline & Population & 76.5 & 23.5 & - & - & 30.4 & 27.9 & 41.7 & $43.4(28.7)$ & 9573 \\
\hline \multirow[t]{2}{*}{ Computer Science } & Respondents & $78.8^{*}$ & $20.3^{*}$ & 0.1 & 0.8 & $33.6^{*}$ & $22.5^{*}$ & $43.9 *$ & $65.4(47.2)$ & 999 \\
\hline & Population & 85.5 & 14.5 & - & - & 22.9 & 26.8 & 50.3 & $65.7(48.5)$ & 5792 \\
\hline \multirow[t]{2}{*}{ History } & Respondents & $53.0^{*}$ & $46.5 *$ & 0.2 & 0.2 & 16.8 & 39.3 & 43.9 & $55.8(39.0)$ & 992 \\
\hline & Population & 62.7 & 37.3 & - & - & 16.4 & 38.3 & 45.3 & $51.9(38.2)$ & 4336 \\
\hline \multirow[t]{2}{*}{ Physics/Astronomy } & Respondents & 79.3 & 19.6 & 0.2 & 1.0 & 17.5 & 18.6 & 63.8 & $52.4(39.6) *$ & 937 \\
\hline & Population & 85.7 & 14.3 & - & - & 18.1 & 19.7 & 62.2 & $51.5(41.7)$ & 5874 \\
\hline \multirow[t]{2}{*}{ Psychology } & Respondents & $46.5^{*}$ & $53.1^{*}$ & 0.2 & 0.2 & 20.7 & 30.4 & 48.9 & $83.8(59.9) *$ & 982 \\
\hline & Population & 54.4 & 45.6 & - & - & 23.1 & 28.7 & 48.2 & $88.2(60.5)$ & 6507 \\
\hline \multirow[t]{2}{*}{ Sociology } & Respondents & 45.6 & 53.7 & 0.2 & 0.4 & 17.5 & 31.9 & 50.6 & $38.7(25.9)$ & 447 \\
\hline & Population & 50.0 & 50.0 & - & - & 22.1 & 29.7 & 48.2 & $40.0(27.3)$ & 2471 \\
\hline
\end{tabular}

TABLE S1. Demographic attributes of faculty in each discipline who provided either of the most important variables to this study. We report proportions for gender and faculty rank and means and standard deviations (in parentheses) for departmental prestige. Significant differences $\left(\chi^{2}\right.$ tests for gender and rank, Kolmogorov-Smirnov tests for prestige) are marked with $*$, indicating $p<0.05$.

graphics to those who provided parental education information (Table S1), but skewed towards being from slightly less prestigious institutions in History (56.6 versus 51.8, Kolmogorov-Smirnov, $D=0.1, p=0.032$ ), and slightly more in Sociology (38.8 versus 40.0, KolmogorovSmirnov, $D=0.1, p=0.039)$.

\section{Survey Questions}

- "In what year were you born?" Drop down of years from 1916 to 1996.

- "During the first 18 years of your life, did your family rent the home in which you lived, or did your family own it (even if supported by a mortgage)?" Options were "We rented a home during all or most of the first 18 years of my life," "We rented and

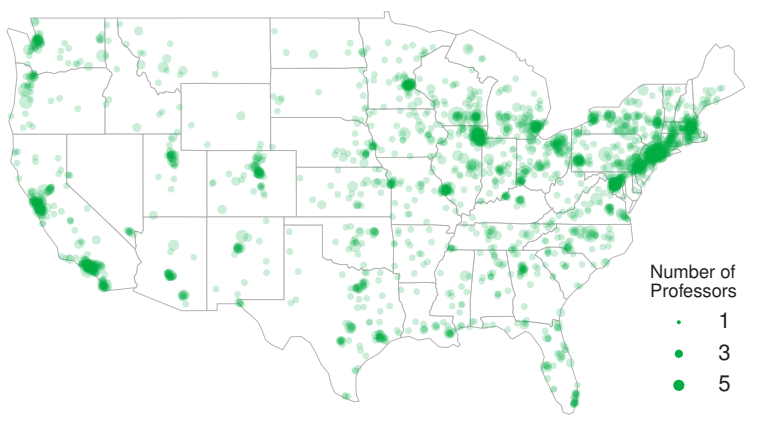

FIG. S1. Geographic plot of respondents by childhood ZIP code. Dot size scales with the number of faculty responses. owned a home about equally often," "We owned a home during all or most of the first 18 years of my life," or "Don't know"

- "Where did you live during the first 18 years of your life? If you lived in the U.S., please let us know in which ZIP code you live the longest." Open text box.

- "Now please think of your parents or legal guardians during the first 18 years of your life and answer the following questions about them. If you grew up with just one parent or legal guardian, please select 'Not applicable' for 'Parent 2'."

- "What are their genders?" Options were "Male," "Female," or "Other identity."

- "What is their highest level of education?" Options were "Elementary: 0-4 years," "Elementary: 5-8 years," "High school: 1-3 years," "High school: 4 years," "College: 1-3 years," "College: 4 or more years," "Master's or professional degree," "Doctoral degree," "Don't know," or "Not applicable / Rather not say."

- "What best describes their employment status during all or most of the first 18 years of your life?" Options were "Employed," "Not employed: stay-at-home parent," "Not employed: could not find job," "Not employed: other reason (e.g. retired, illness, ...)," "Don't know or something else," or "Not applicable / Rather not say."

- "What is your gender?" Options were "Male," "Female," "Other identity," or "Prefer not to say." 
- "What is your race or origin? Please select one or more responses." Options were "White," "Hispanic, Latino, or Spanish origin," "Black or African American," "Asian," "American Indian or Alaska Native," "Native Hawaiian or other Pacific Islander," "Some other race or origin," or "Prefer not to say."

- "Please rate support and encouragement you received for your academic career from people below, on a scale from 1 (none at all) to 5 (a lot). If some of those people were not present in your life, please choose Not applicable." Category analyzed was "your parents" with options 1-5 and "Not Applicable."

\section{B. Matching to Census, IRS, and NSF Data}

Comparing the education and income of the parents of faculty with the overall United States population involves linking responses to publicly available education and income data. Responses were matched either by the year faculty were born or the year they began their first tenure-track job, to the appropriate year of data release.

For example, the National Science Foundation's Survey of Earned Doctorates (NSF SED) provides information on the educational attainment of the parents of doctoral recipients every five years from 1993 to 2018 (Table S4). Survey responses were matched to the closest available data. In many cases (32.6\% of responses) this was 1993, the earliest year available from the NSF.

Data on the urban or rural classifications of ZIP codes were obtained from the decennial U.S. Census presented by the Integrated Public Use Microdata Series (IPUMS) National Historical Geographic Information System (NHGIS) 42] (Table S5). Responses were linked by the closest year to when faculty were 21 years old, to represent the ZIP code's characteristics close to when the respondent was growing up. The majority of responses $(67.9 \%)$ were matched to the earliest data release (1990).

The American Community Survey provides estimates of the highest educational level attained by all adults (25 years or older) in the U.S. [56] (Table S6). This data is available on a yearly basis starting in 1993 35. We link this data to responses by the birth year of faculty to compare the parents of faculty with the U.S. adult population at the time of their birth. Almost all responses are linked to the earliest release available.

Lastly, it is generally difficult to estimate income distributions for geographic locales, especially without a direct connection to census tract. Our approach using ZIP codes is common, in part because people can recall their ZIP code more readily than street address or census tract. The U.S. Internal Revenue Service (Table S7) reports the total income and number of returns for each ZIP code in the U.S. from 1998 to 2018. Responses were linked by the closest year to when faculty were 21 years old, to approximate the wealth of a ZIP code during the person's childhood. Most responses (79.0\%) were linked to the earliest release since the average year the faculty we surveyed were born was 1967 . The IRS provides earlier data on the county level (from 1989 on; 87]), and state levels (from 1954 on; 88]). Because ZIP codes are based on the mail distribution needs of USPS, they only roughly correspond to other geographic locales 60]. For example, they change shape over time, and can span states or counties. Altogether, this means linking ZIP codes to historical income on the county and state level is difficult and requires the boundaries of ZIP codes and counties, and population estimates for each over time.

\section{Comparing Survey Household Estimates with Population Estimates of Education}

Assuming a two-parent household where each parent has an equal chance of having a $\mathrm{PhD}$, and the percentage of U.S. adults without a Ph.D is $99.1 \%$ (Table I), we estimate the percentage of children who have at least one $\mathrm{PhD}$ parent is roughly $1.8 \%$ (i.e., $1-(0.991 \cdot 0.991)=$ 0.018). This value divided by the proportion of faculty with at least one $\mathrm{PhD}$ parent returns a lower bound of $12(0.222 / 0.018)$. Considering a single parent household, the upper bound becomes $25(0.222 / 0.009$; denominator is the percentage of adults with a $\mathrm{PhD})$.

Obtaining precise bounds on this rate is difficult, as it depends on family structure and the strength of educational homogamy [89, and must account for the generally declining fertility by education level 90. Based on current estimates of these factors, along with our data's overestimate of the U.S. adult population's PhD attainment rates, we expect the true value to be in the upper end of this range.

Unlike the U.S. Census data, the NSF SED reports the highest educational attainment of either parent, consistent with our results. Surveyed faculty are 1.9 times more likely as $\mathrm{PhD}$ recipients to have a parent who holds a $\operatorname{PhD}(0.222 / 0.188)$.

\section{Relationships between SES, Age, and Geographic Distance}

A scholar's search for a faculty job may be influenced by family SES, either by shaping how long they are willing to search for scarce tenure-track employment, or by geographically limiting which institutions they can apply to for jobs. Faculty who reported at least one of their parents holds a $\mathrm{PhD}$ are slightly younger at the start of the tenure-track job than those faculty whose parents do not hold a $\mathrm{PhD}$ (33.1 versus 33.6 years old; $t=-3.0, N=6951, p=0.002)$. They traveled about the same distance from home though (873 versus 835 miles; Kolmogorov-Smirnov, $D=0.0, N=7209, p=0.997)$. 


\begin{tabular}{l|ccccccc}
\hline \hline & Elementary & Some HS & HS & Some College College Masters PhD \\
\hline Anthropology Women Professors & 0.6 & 1.7 & 16.9 & 5.6 & 18.5 & 32.0 & 24.7 \\
Anthropology Men Professors & 1.2 & 2.9 & 13.3 & 8.7 & 20.2 & 31.8 & 22.0 \\
\hline Biology Women Professors & 1.7 & 2.6 & 9.7 & 12.5 & 18.9 & 30.5 & 24.0 \\
Biology Men Professors & 3.9 & 3.7 & 16.7 & 11.2 & 19.8 & 23.8 & 20.9 \\
\hline Business Women Professors & 0.3 & 2.4 & 11.9 & 7.6 & 26.5 & 32.3 & 18.9 \\
Business Men Professors & 3.2 & 3.7 & 15.8 & 8.8 & 23.0 & 29.9 & 15.6 \\
\hline CS Women Professors & 1.5 & 1.5 & 11.3 & 4.9 & 28.1 & 21.7 & 31.0 \\
CS Men Professors & 3.7 & 3.9 & 10.7 & 9.8 & 19.8 & 27.4 & 24.7 \\
\hline History Women Professors & 1.7 & 1.2 & 7.9 & 5.7 & 15.3 & 37.3 & 30.9 \\
History Men Professors & 1.5 & 1.5 & 12.8 & 10.7 & 18.5 & 31.9 & 23.1 \\
\hline Physics/Astronomy Women Professors & 3.3 & 3.8 & 7.7 & 12.0 & 13.1 & 31.1 & 29.0 \\
Physics/Astronomy Men Professors & 4.3 & 4.2 & 13.1 & 9.4 & 19.6 & 26.3 & 23.1 \\
\hline Psychology Women Professors & 0.8 & 1.7 & 17.1 & 8.8 & 17.1 & 31.2 & 23.3 \\
Psychology Men Professors & 2.6 & 2.6 & 17.4 & 11.2 & 17.1 & 31.2 & 17.8 \\
\hline Sociology Women Professors & 1.7 & 2.1 & 17.1 & 5.4 & 17.5 & 36.7 & 19.6 \\
Sociology Men Professors & 2.0 & 3.4 & 17.6 & 8.8 & 16.7 & 34.3 & 17.2 \\
\hline \hline
\end{tabular}

TABLE S2. Percentages of faculty by gender and discipline with their parents' highest held degree.

\begin{tabular}{|c|c|c|c|c|c|c|c|}
\hline & Elementary & Some HS & $\mathrm{HS}$ & Some College & College & Masters & $\mathrm{PhD}$ \\
\hline White Women Professors & 0.9 & 1.7 & 12.1 & 7.3 & 19.5 & 32.9 & 25.5 \\
\hline Black Women Professors & 4.9 & - & 17.5 & 14.6 & 11.7 & 36.9 & 14.6 \\
\hline Hispanic Women Professors & 2.3 & 2.3 & 13.7 & 15.3 & 15.3 & 31.3 & 19.8 \\
\hline Asian Women Professors & 2.4 & 4.4 & 7.3 & 12.5 & 19.4 & 30.2 & 23.8 \\
\hline American Indian / Native Women Professors & - & 5.3 & 21.1 & 10.5 & 10.5 & 36.8 & 15.8 \\
\hline White Men Professors & 2.4 & 2.5 & 15.2 & 9.6 & 19.2 & 29.1 & 22.0 \\
\hline Black Men Professors & 7.4 & 8.4 & 15.8 & 12.6 & 9.5 & 26.3 & 20.0 \\
\hline Hispanic Men Professors & 6.9 & 6.4 & 17.0 & 9.6 & 18.1 & 27.1 & 14.9 \\
\hline Asian Men Professors & 7.3 & 8.4 & 7.5 & 12.4 & 25.3 & 23.4 & 15.7 \\
\hline American Indian / Native Men Professors & - & 3.4 & 17.2 & 10.3 & 20.7 & 37.9 & 10.3 \\
\hline
\end{tabular}

TABLE S3. Percentages of faculty by race / ethnicity and gender with their parents' highest held degree. Dashes denote zero respondents.

\begin{tabular}{cccccc}
\hline \hline $\begin{array}{c}\text { Year of } \\
\text { US Census }\end{array}$ & Avg. Min. Max. & $N$ \\
\hline 1990 & 1960 & 1916 & 1974 & 4985 \\
2000 & 1979 & 1975 & 1984 & 1978 \\
2010 & 1987 & 1985 & 1999 & 379 \\
\hline \hline
\end{tabular}

TABLE S5. Number of responses $(N)$ linked to each release of the U.S. Census 42 describing the percentage of the urban and rural population per ZIP code. The average, minimum, and maximum year faculty were born across linked responses.

\begin{tabular}{ccccc}
\hline \hline $\begin{array}{c}\text { Year of } \\
\text { NSF SED }\end{array}$ & Avg. Min. Max. & $N$ \\
\hline 1993 & 1985 & 1928 & 1995 & 2326 \\
1998 & 1998 & 1996 & 2000 & 868 \\
2003 & 2003 & 2001 & 2005 & 985 \\
2008 & 2008 & 2006 & 2010 & 985 \\
2013 & 2013 & 2011 & 2015 & 1310 \\
2018 & 2017 & 2016 & 2020 & 647 \\
\hline \hline
\end{tabular}

TABLE S4. Number of responses $(N)$ linked to each release of NSF SED [36, which contains the educational attainment of the parents of doctoral recipients. The average, minimum, and maximum tenure track start year across linked responses. 


\begin{tabular}{ccccc}
\hline \hline $\begin{array}{c}\text { Year of } \\
\text { ACS }\end{array}$ & Avg. Min. Max. & $N$ \\
\hline 1993 & 1967 & 1916 & 1992 & 7338 \\
1996 & 1998 & 1996 & 1999 & 4 \\
\hline \hline
\end{tabular}

TABLE S6. Number of responses $(N)$ linked to the American Community Survey [35, 56, which reports the educational attainment of adults (25 years and older) in the United States. The average, minimum, and maximum year faculty were born across linked responses.

\begin{tabular}{cccccc}
\hline \hline Year of & & & & & \\
IRS & Avg. Min. Max. & $N$ \\
\hline 1998 & 1963 & 1916 & 1978 & 5802 \\
2001 & 1980 & 1979 & 1980 & 394 \\
2002 & 1981 & 1981 & 1982 & 422 \\
2004 & 1983 & 1983 & 1983 & 177 \\
2005 & 1984 & 1984 & 1984 & 168 \\
2006 & 1985 & 1985 & 1985 & 118 \\
2007 & 1986 & 1986 & 1986 & 111 \\
2008 & 1987 & 1987 & 1987 & 61 \\
2009 & 1988 & 1988 & 1988 & 44 \\
2010 & 1989 & 1989 & 1989 & 25 \\
2011 & 1990 & 1990 & 1990 & 11 \\
2012 & 1991 & 1991 & 1991 & 4 \\
2013 & 1992 & 1992 & 1992 & 1 \\
2017 & 1996 & 1996 & 1996 & 2 \\
2019 & 1999 & 1999 & 1999 & 2 \\
\hline \hline
\end{tabular}

TABLE S7. Number of responses $(N)$ linked to IRS data releases [86, which reports the total income and number of returns reported per ZIP code. The average, minimum, and maximum year faculty were born across linked responses. 